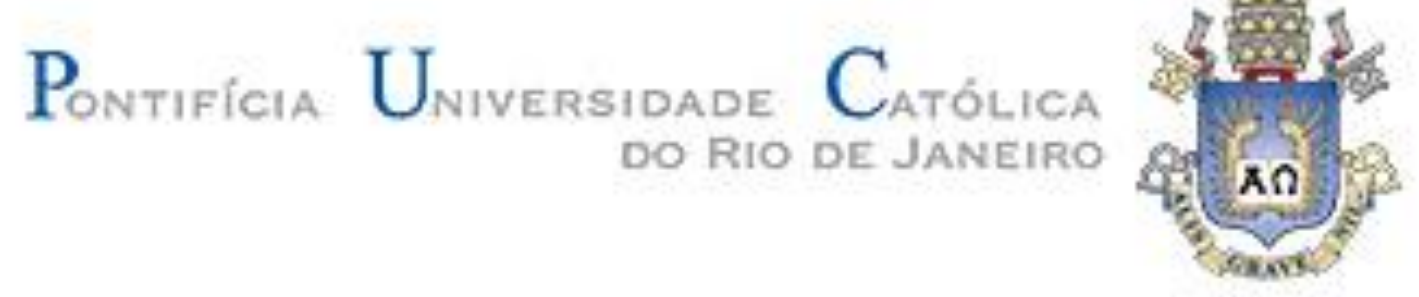

Adriano Lourenço da Silva

\begin{abstract}
A política e o psicanalista: um percurso histórico
\end{abstract}

Monografia de Conclusão de Curso

Monografia de Conclusão de Curso apresentada ao Programa de Pós Graduação em Psicologia do Departamento de Psicologia como parte dos requisitos parciais para a obtenção do título de Especialista em Psicologia Clínica.

Orientador: Maria da Glória Schwab Sadala

Rio de Janeiro Dezembro de 2018 
Adriano Lourenço da Silva

\section{A política e o psicanalista: um percurso histórico}

Monografia de Conclusão de Curso apresentada ao Programa de Pós Graduação em Psicologia do Departamento de Psicologia como parte dos requisitos parciais para a obtenção do título de Especialista em Psicanálise Clínica.

Maria da Glória Schwab Sadala

Departamento de Psicologia - PUC-Rio

Nome do membro de banca

Departamento de Psicologia - PUC-Rio

Nome do membro da banca

Departamento de Psicologia - PUC-Rio

Rio de Janeiro, dia 10 de dezembro de 2018. 
Todos os direitos reservados. É proibida a reprodução total ou parcial do trabalho sem a autorização da universidade, do autor e do orientador.

\section{Adriano Lourenço da Silva}

Adriano Lourenço da Silva é Psicólogo, coordenador do Círculo de Estudos da Ideia e da Ideologia (CEII) e mestrando em Psicologia Clínica pela Pontifícia Universidade do Rio de Janeiro. Desenvolve estudos nas áreas de psicanálise e política. E-mail: adr.lourenco@gmail.com.

Ficha catalográfica

Silva, Adriano Lourenço da.

A política e o psicanalista: um percurso histórico. Adriano Lourenço da Silva; orientador. $42 f l-2019$.

12345 f. II. (color); $30 \mathrm{~cm}$.

Monografia (especialização) - Pontifícia Universidade Católica do Rio de Janeiro. Departamento de Psicologia, 2019.

Inclui bibliografia.

1. Psicologia - Monografia. 2. Psicanálise. 3. Política. 4. História da psicanálise. 5. Freud.. I. Maria da Glória Schwab Sadala. II. Pontifícia Universidade Católica do Rio de Janeiro. Departamento de Psicologia. III. Título. 
Dedico este trabalho à Ilda Triani 


\section{Agradecimentos}

Agradeço aos meus pais, Sebastião e Neia, irmãos, Alessandro, Lourena, Thaiane e Raiane e amigos pela aposta e parceria.

À Professora Maria Luiza Rodrigues, pela transmissão afetuosa da psicanálise.

À Professora Glória Sadala pela orientação nos estudos e apoio na vida.

À professora Maria Anita Carneiro Ribeiro pelo desejo de transmissão da psicanálise em solo iguaçuano.

Ao Círculo de Estudos da Ideia e da Ideologia, pela acolhida e abertura de possibilidades.

Ao Paulinho Alves e Rafael Alves, pela amizade.

Ao Gabriel Tupinambá pelo carinho e incentivo.

À Estela Willeman pela dedicação e compromisso.

E, a Bill e Bob pela criação, e a todos a que a ela se destinam. 
"Enquanto os homens exercem

Seus podres poderes

Motos e fuscas avançam

Os sinais vermelhos

E perdem os verdes

Somos uns boçais

(...)

Será que nunca faremos senão confirmar

A incompetência da América católica

Que sempre precisará de ridículos tiranos?"

Caetano Veloso

"Podres Poderes" 


\section{Resumo}

Silva, Adriano Lourenço da. Sadala, Maria da Glória Schwab A política e o psicanalista: um percurso histórico. Rio de Janeiro, 2018. Monografia de Conclusão de Curso de Especialização em Psicologia Clínica. - Departamento de Psicologia, Pontifícia Universidade Católica do Rio de Janeiro.

Este trabalho visa discutir a atuação dos psicanalistas frente à questões políticas de seu tempo. Traremos para isso, alguns fatos políticos importantes como a ascenção do nazismo na época de Freud e do advento das guerras, bem como a reação do psicanalista vienense a estes fatos. Abordaremos também a tentativa de regulamentação da profissão de psicanalista no Brasil e dois fatos importantes na França contemporânea: a criação da ZADIG que trata de assuntos políticos e a emenda Accoyer que visava restringir a atuação de psicanalista no país francês.

\section{Palavras-chave:}

Psicanálise; política; democracia; ZADIG; regulamentação 


\section{Abstract}

Silva, Adriano Lourenço da. Sadala, Maria da Glória Schwab Politics and the psychoanalyst: a historical journey. Rio de Janeiro, 2018. Monograph of Conclusion of Specialization Course in Clinical Psychology. - Department of Psychology, Pontifical Catholic University of Rio de Janeiro.

This work aims to discuss the psychoanalysts' action in relation to the political issues of their time. We will bring some important political facts such as the rise of Nazism in Freud's time and the advent of wars, as well as the Viennese psychoanalyst's reaction to these facts. We will also address the attempt to regulate the profession of psychoanalyst in Brazil and two important facts in contemporary France: the creation of the ZADIG dealing with political issues and the Accoyer amendment aimed at restricting the performance of a psychoanalyst in the French country.

\section{Keywords:}

Psychoanalysis; politics; democracy; ZADIG; regulation 
Sumário

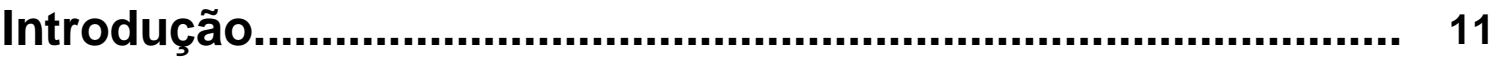

1. Percurso histórico............................................................... 19

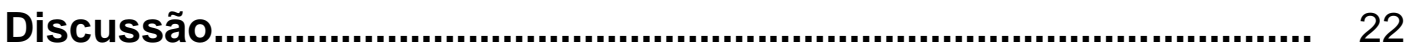

Áustria: Estado-museu................................................................. 27

2. Cenário contemporâneo ...................................................... 31

2.1.Tentativa de regulamentação ...................................................... 31

2.1.1. Emenda Accoyer......................................... 32

2.2. O exemplo de Massimo Recalcati............................................. 34

2.3. Criação da ZADIG.................................................................... 36

2.4. Proposição de nove de outubro de 1967.............................. 37

Considerações Finais.................................................................... 39

Referências Bibliográficas...................................................... 41 


\section{Siglário}

CBO Classificação Brasileira de Ocupações

$\mathrm{PCl} \quad$ Partido Comunista Italiano

UFSC Universidade Federal de Santa Catarina

ZADIG Zero Abjection Democratic International Group 


\section{Introdução}

Os temas sobre política inundam os noticiários do mundo Ocidental. No âmbito democrático do Estado de direito, os representantes escolhidos pela maioria da população deliberam (ou deveriam deliberar) em prol do comum, mas não sem pontos de honesta divergência, não sem debates.

As decisões tomadas em assembleias podem afetar não só as comunidades que as representam, mas, alguns casos, como das políticas de proteção ao meio-ambiente, por exemplo, excedem fronteiras e são pautas globais - os chamados direitos de terceira e quarta geração de Norberto Bobbio $^{1}$, direitos mais identificados com direitos coletivos e direitos difusos, respectivamente. Imigração, manipulação genética, mercado financeiro, soberania dos países e as guerras também são exemplos de decisões políticas que deságuam em territórios desconhecidos.

O que o psicanalista pode apontar sobre estes debates tão candentes? Desde já, primando pelos princípios da transparência na construção da ciência e dos debates em torno dela, cabe evidenciar que o autor da presente monografia se implica na questão a partir de uma dupla pertença: enquanto cidadão e também como profissional do campo em questão.

Psicanálise e política dividem ainda semelhanças em suas raízes conflituosas e controversas. Se a vocação científica da psicanálise é posta à prova pela dificuldade em ser verificável, reprodutível nos cânones das ciências da natureza, as ditas ciências duras, abrindo uma brecha para o antagonismo e a inconsistência; da mesma forma, a teoria política também não fornece garantias quando se materializa em práxis, dependendo de tantas variáveis quanto se pode conjecturar, como: o devir histórico, os vetores de forças sociais imbricados na totalidade histórica, as relações sociais travadas no bloco histórico.

Do ponto de vista do método do materialismo histórico crítico dialético, é fundamental conhecer o máximo possível das características do modo de produção e reprodução social, as determinações sociais, históricas,

\footnotetext{
${ }^{1}$ BOBBIO, Norberto. A era dos direitos. Nova ed. — Rio de Janeiro: Elsevier, 2004
} 
econômicas, culturais e outras de um determinado momento e perquirir a conexão existente entre elas para, só assim, fazer alguma afirmação a respeito, uma vez que

$\mathrm{Na}$ produção social da própria vida, os homens contraem relações determinadas, necessárias e independentes da sua vontade, relações de produção estas que correspondem a uma etapa determinada de desenvolvimento das suas forças produtivas materiais. A totalidade dessas relações de produção forma a estrutura econômica da sociedade, a base real sobre a qual se levanta uma superestrutura jurídica e política e à qual correspondem formas sociais determinadas de consciência. $O$ modo de produção da vida material condiciona o processo em geral de vida social, político e espiritual. Não é a consciência dos homens que determina o seu ser, mas, ao contrário, é o seu ser social que determina sua consciência. Em uma certa etapa de seu desenvolvimento, as forças produtivas materiais da sociedade entram em contradição com as relações de produção existentes ou, o que nada mais é do que a sua expressão jurídica, com as relações de propriedade dentro das quais aquelas até então se tinham movido. (MARX, 1982, p. 25).

E ainda,

Os homens são os produtores de suas representações, de suas idéias e assim por diante, mas os homens reais, ativos, tal como são condicionados por um determinado desenvolvimento de suas forças produtivas e pelo intercâmbio que a ele corresponde [...]. A consciência não pode ser jamais outra coisa do que o ser consciente e o ser dos homens é o seu processo de vida real. [...] Não é a consciência que determina a vida, mas a vida que determina a consciência. (MARX, ENGELS, 2007:87).

Ademais, ainda acerca de uma possível concepção neutra das ciências naturais versus uma intangibilidade das ciências sociais, consideramos que tanto o mito da neutralidade cientifica já se tornou algo superado como primamos mais por uma perspectiva que aponta para a importância da transparência na construção e na transmissão dos saberes científicos.

Bourdieu, em sua conferência de "os usos sociais da ciência", algo importante para não se perder de vista, comum na esfera da produção acadêmica, é que os jogos de poder nesta esfera e que põem em disputa os modelos explicativos 
não perdem como foco o amplo debate e, por vezes, atendem mais às necessidades endógenas do próprio campo intelectual do que demandas sociais.

Diria o francês que

... por exemplo, que a retórica da 'demanda social' que se impõe, particularmente numa instituição científica que reconhece oficialmente as funções sociais da ciência, inspira-se menos numa preocupação real em satisfazer as necessidades e as expectativas de tal ou qual categoria de 'clientes' (grandes ou pequenos agricultores, indústrias agroalimentícias, organizações agrícolas, ministérios, etc.), ou mesmo em ganhar assim seu apoio, do que assegurar uma forma relativamente indiscutível de legitimidade e, simultaneamente, um acréscimo de força simbólica nas lutas internas de concorrência pelo monopólio da definição legítima da prática científica (poderse-ia, nessa perspectiva, proceder-se a uma análise metódica relacionando as tomadas de posições $e$ as posições, os atos dos Estados gerais e o desenvolvimento agrícola de 1982). [...].

O que a análise sociológica traz, e que , num certp sentido, muda tudo, é antes de qualquer coisa uma colocação em perspectiva sistemática de visões perspectivas que os agentes produzem para as necessidades de suas lutas práticas no interior do campo, e que, a despeito de tudo o que eles fazem para 'universalizá-las', como no exemplo da evocação da 'demanda social', encontram seu princípio nas particularidades de uma posição no próprio interior do campo, e que assim postas em seus eixos mudam radicalmente de sentido e de função. (BOURDIEU, 2004: 47).

Ainda assim, consideramos que, numa intervenção analítica, os efeitos serão verificados à posteriori, ou Nachstraglish, como conceituou Freud. Desse modo, como poderíamos mensurar a eficácia de uma dada intervenção se os efeitos desta só serão visualizados posteriormente? E ainda, sem um prazo específico para isso, respeitando apenas a singularidade do sujeito do inconsciente?

No cenário contemporâneo, o espaço reivindicado pelas Escolas de psicanálise como sendo o lugar strictu sensu de transmissão do saber analítico chama para si a responsabilidade de proteger a psicanálise de interferências outras como a de um academicismo conservador, por exemplo.

A proposta psicanalítica intenciona justamente convidar essas contradições para si na medida em que o sujeito também é permeado por contradições desta maneira. Na querela entre inconsciente e recalque não há vencedores claros, o mal-estar e a falta hão de ser presentes. 
No jogo político podemos notar algumas semelhanças. Percebemos cisões e contradições abundantes quando falamos do cenário político. É comum, usando o exemplo brasileiro, a "dança das cadeiras" dos partidos, de acordo com o interesse de seus participantes.

No caso específico de partidos ou segmentos de lutas contra opressões sociais orientadas pelo marxismo, a prática revolucionária da "luta de classes" dá a tônica do que seria o desafio a ser vencido: no tenso jogo de forças entre as classes, a condição de superação estaria na eliminação das classes sociais a partir de um processo de diminuição ou supressão destas diferenças, dependendo da orientação sociopolítica - se mais ou menos radical em sua acepção da teoria da revolução.

Em Freud, contudo, a princípio - numa abordagem individual, não há indicação de perspectivas de superação de condição de classe, o sujeito experimentaria, no máximo, uma forma distinta de lidar com seu inconsciente. No entanto, nem o sujeito é descolado da realidade e nem o analista pode desconsiderar as estruturas sociais que determinam as existências singulares.

Cabe, a despeito de uma apreensão míope do sujeito e seus processos, a consideração constante de aspectos da totalidade e das particularidades incidindo naquela singularidade expressa enquanto sujeito único e coletivo ao mesmo tempo.

Em obras como Mal estar na civilização e Totem e Tabu e Psicologia das massas e análise do Eu, Freud dá indicações consistentes acerca de como eventos de amplitude global estão implicados nos sujeitos singulares nos processos, por exemplo, de dissolução ou fortalecimento do ideal civilizatório e como isso muda os rumos das relações sociais em nível micro e macrossocial a partir do início do século XX.

Convocado a se posicionar para além da sua condição de cidadão, como deve ser a atuação dos psicanalistas frente aos novos desafios de seu tempo? Será possível ficar alheio a questões tão atuais? Por outro lado: há alguma indicação explícita de qual deveria ser a postura pública a ser evitada por este profissional? 
A motivação principal para este trabalho se dá pela criação na $Z_{A D I G}{ }^{2}$ na França, em 2018, e também pelo posicionamento polêmico do psicanalista francês Jacques Alain-Miller ao dizer que os psicanalistas devem "fechar a caixa de pandora da psicanálise", não permitindo que ela seja apropriada em alguns outros contextos, como o contexto político partidário, por exemplo.

Neste trabalho pretende-se, ainda que de forma breve, analisar 0 posicionamento de Sigmund Freud ante algumas questões de seu tempo através dos indícios colhidos em depoimentos, documentos, cartas, relatos públicos disponíveis para análise documental destes conteúdos.

A atuação de Freud nestes termos, pode ser trazida por Renato Mezan, (1985), quando afirma que:

Longe de viver num país tolerante e democrático, Freud está no centro de lutas extremamente acirradas, na mira de regimes autoritários e obscurantistas, e que neste contexto a coerção exterior, se não o impede de publicar O Futuro de Uma Ilusão nem O Mal-Estar na Cultura, o dissuade de dar à luz o estudo sobre Moisés, temendo que um ataque frontal contra a religião, nas circunstâncias políticas de Viena após a guerra civil de 1934, acarretasse a proibição do exercício da psicanálise no país. (MEZAN, p.439).

Ainda para Mezan, a atuação de Freud estende-se, ainda, neste contexto político, da seguinte forma:

a elaboração freudiana se situa num momento particularmente agudo do processo político e ideológico da sociedade em que vive; mesmo se a presença destes conflitos e contradições só lateralmente aparece em seus escritos, vejo aí mais o índice de uma dificuldade do que a prova de seu apolitismo. Não obstante, o efeito mais imediato da ascensão do fascismo e do nazismo é conduzir o fundador da psicanálise a se colocar a questão do anti-semitismo e a procurar esclarecê-la a partir do exame da religião em geral. Moisés e o Monoteísmo ocupa incessantemente seu espírito por mais de quatro anos, entre 1934 e 1938, e este texto enigmático é por assim dizer seu testamento no que tange à análise da cultura. (MEZAN, P. 439)

\footnotetext{
${ }^{2}$ A criação da Rede La Movida Zadig (acrônimo de Zero Abjection Democratic International Group) ocorreu em 15 de maio de 2017, de acordo com Angelina Harari. Conteúdo disponível em: https://www.ebp.org.br/correio express/000/texto2.html. Acesso em 25 de fevereiro de 2019.
} 
Longe de oferecer respostas cabais ou teses inquestionáveis, o objetivo aqui, então, é buscar na análise da atuação do próprio Freud, bases para orientar/inspirar a direção de analistas contemporâneos.

Cabe lembrar que, em A ideologia alemã (escrita em 1845/1846, mas só publicada em $1932^{3}$ ), surge uma importante formulação das concepções de Marx e Engels, baseada em pressupostos reais dados pelas condições materiais dos indivíduos e que será melhor desenvolvida em O 18 Brumário de Luis Bonaparte. (MARX, 2011).

Segundo eles, em A ideologia.... "não se parte daquilo que os homens dizem, imaginam ou representam, tampouco os homens pensados, imaginados ou representados para, a partir daí, chegar aos homens de carne e osso; partese dos homens realmente ativos [...], do seu processo de vida real" (MARX; ENGELS, 2007: 94).

Na base dessas ideias, está um argumento essencial:

Os homens são os produtores de suas representações, de suas idéias e assim por diante, mas os homens reais, ativos, tal como são condicionados por um determinado desenvolvimento de suas forças produtivas e pelo intercâmbio que a ele corresponde [...]. A consciência não pode ser jamais outra coisa do que o ser consciente e o ser dos homens é o seu processo de vida real. [...] Não é a consciência que determina a vida, mas a vida que determina a consciência. (MARX; ENGELS, 2007: 100).

É n'O 18 Brumário, imbuído da concepção de história como contraditória e sempre num estado de processo, de movimento, que Marx coroa seu pensamento, junto a Engels: "Os homens fazem a sua própria história, mas não a fazem como querem; não a fazem sob circunstâncias de sua escolha e sim sob aquelas com que se defrontam diretamente, legadas e transmitidas pelo passado" (MARX, 2011: 20).

Sendo assim, muito embora sua atuação individual, personalíssima, contenha determinações de elementos específicos do momento histórico que viveu, e guardadas as particularidades do momento histórico, de sua condição de classe, religiosa, raça e orientação sexual e sob o risco do anacronismo, pressupomos que o posicionamento do primeiro teórico que estruturou 0

\footnotetext{
${ }^{3}$ Cf. Netto, 2009: 13.
} 
inconsciente e que, durante sua obra, se debruçou sobre temas afins à civilização, forneça algumas pistas para a atuação os analistas dos dias de hoje.

Alguns pontos na e da política representativa contemporânea tocam e afetam diretamente a práxis do analista - como, a nova e velha tentativa de regulamentação de seu ofício no Brasil ${ }^{4}$, por exemplo. Neste aspecto, falaremos do processo de regulamentação da profissão de psicanalista no Brasil e da criação da ZADIG na França, seção da Associação de Psicanálise Mundial que trata exclusivamente de temas políticos.

Para além desta questão pontual, que serão retomadas no decorrer do presente trabalho, questões outras também serão abordadas, como 0 posicionamento político em público do analista, e das escolas de transmissão de psicanálise, enquanto formadoras de novos analistas A metodologia deste trabalho é qualitativa e os procedimentos de investigação se basearão na revisão bibliográfica de autores ligados à psicanálise, que tiveram em sua produção um enfoque histórico, contextualizando alguns momentos importantes dessa junção entre psicanálise e política de modo a subsidiar uma tentativa de análise documental na modalidade análise de conteúdo ${ }^{5}$.

Dada a escassa produção nestes campos, traremos essencialmente poucos autores para dialogar. Em especial, para o presente texto, selecionamos o psicanalista brasileiro Renato Mezan e o filósofo esloveno MlalenDolar, este último com produção mais recente.

$\mathrm{Na}$ primeira parte do trabalho apresentaremos brevemente o contexto sociohistórico da Áustria do final do século XIX, época do nascimento de Freud e, posteriormente, do surgimento da psicanálise enquanto novidade científica. Percorreremos os acontecimentos políticos relativos a esse período e faremos um inventário do nível dos impactos destes acontecimentos na obra freudiana. Na mesma trilha da técnica de análise comparada, traremos um breve recorte

\footnotetext{
${ }^{4}$ A última tentativa de que se tem notícia se constitui em um Projeto de Lei de 2018 apresentado pelo senador Telmário Mota. Disponível em: https://legis.senado.leg.br/sdleggetter/documento?dm=7644824\&disposition=inline. Acesso em 25 de fevereiro de 2019.

${ }^{5}$ Cf. Bardin, 2011; Minayo, 1994; Marconi e Lakatos, 1992, e outros.
} 
históricodissertando sobre as contingências e limites impostos pela instauração do regime totalitário do nazismo na Europa, as guerras ocorridas do períodoe, ainda,cotejaremos estes processos sociais com os posicionamentos públicos de Freud e, por fim, a título de curiosidade e enriquecimento da tentativa de aproximação com o que Geertz chama de descrição densa. Tal relatoculminarána tentativa quase totalmentebem sucedida de Freud de alijamento do papel de protagonismo de Gross da primeira fase da história do movimento psicanalítico.

$\mathrm{Na}$ segunda sessão deste textoabordaremos algumas questões selecionadas da política contemporânea visando problematizar o atual cenário e, a partir dos indícios analisados nos relatos históricos supracitados, indicaremos a direção encontrada naanálise de conteúdo dos documentos e fatos históricos analisados, podendo, assim, indicar razoáveis indícios para atuação de novos analistas frente aos desafios contemporâneos. 


\section{Percurso histórico}

$\mathrm{Na}$ experiência analítica, "a dialética do desejo não é individual" ${ }^{6}$ (LACAN, 1998: 56). Apesar da práxis do psicanalista se dar no um-a-um do setting, o sujeito falante (LACAN (1967)(e sujeito em psicanálise é sempre o sujeito do desejo) é envolto no mar inconsciente do discurso do Outro ${ }^{7}$, o que torna a relação (ou as relações) sempre inserida(s) no laço social (FREUD, 1996) $)^{8}$.

Freud já havia tecido as bases desta proposta em 1921, no texto Psicologia das massas e análise do Eu, quando afirmou que "a psicologia individual é também, desde o início, psicologia social, num sentido ampliado, mas inteiramente justificado", trazendo a importância de o analista compreender que os impactos da estrutura social atuam na formação da subjetividade do sujeito.

Fez tal consideração sem tecer uma relação direta de causa e efeito, mas deveras atento para as reverberações causadas nas duas vias: do divã à polis e, porque não, da polis ao divã?

A partir de Psicologia de grupo e a análise do ego, o fundador da Psicanálise estabelece a relação entre a Psicologia do indivíduo e a Psicologia social. Para Freud,

Algo mais está invariavelmente envolvido na vida mental do indivíduo, comum modelo, [...] de maneira que, desde o começo, a psicologia individual, nesse sentido ampliado mas inteiramente justificável das palavras, é, ao mesmo tempo, também psicologia social" (FREUD, 1996: 81).

Esse "algo mais" do qual fala Freud (1996) em Totem e Tabu, pode ser pensado como um laço social, ou seja, aquilo que permite ao sujeito se relacionar com o outro e obter satisfação pulsional.

\footnotetext{
${ }^{6}$ LACAN, J. Função e campo da fala e da linguagem. In: Escritos. Rio de Janeiro: Jorge Zahar, 1998.

${ }^{7}$ CfLACAN, J.(1985, 1979a, 1979b).

${ }^{8}$ FREUD, S. Totem e tabu. Rio de Janeiro: Imago, 1996. (Primeira edição em 1913).
} 
Quando o sujeito consegue se enlaçar ao outro, considerando que ali há alguém a quem endereçar seu afeto, é possível falar de um bem-estar social, é possível considerar a presença de um sujeito inserido no discurso social.

Já em O mal-estar na civilização, Freud (1930[1929]/1996) afirma que as relações humanas são a maior causa de sofrimento na vida. $O$ autor resgata 0 provérbio romano "O homem é o lobo do homem" para falar da agressividade inerente ao homem e que se constitui como um enorme impedimento à civilização.

A afirmação freudiana de que é preciso limitar os instintos humanos agressivos aponta para a questão de como se manter o laço social. Faz-se necessário ao sujeito renunciar a uma parte da satisfação pulsional para garantir sua permanência na sociedade.

Na interpretação de Lacan (1969/1992), descrita a seguir, a constituição do laço social implica em aceitar a perda de uma parcela de algo, a saber, o gozo.

Se o avanço teórico de Freud se deu pelo recurso da fundamentação clínica, então não the passou despercebido que não existe clínica sem sujeito e que este se constitui pelos atravessamentos em jogo em suas relações.

E por não haver clínica sem sujeito, os atravessamentos sociais precisam ser igualmente teorizados, na qualidade de serem causa e consequência do mal-estar.

O título do trabalho indica que privilegiaremos uma análise do cenário político e a compreensão do espectro de interferência da ação dos psicanalistas enquanto ato político, entenderemos aqui enquanto ato político qualquer ação advinda de psicanalistas que se posicionem claramente enquanto cidadão ou que pensem sua prática no contexto político da sociedade.

É importante salientar que se trata aqui não da política da psicanálise ${ }^{10}$,mas sim do desdobramento do fazer político dos psicanalistas.

\footnotetext{
${ }^{9}$ Este frase foi tornada célebre pelo filósofo inglês Thomas Hobbes em sua obra "Leviatã", publicada em 1651, no entanto, a frase original é da autoria do dramaturgo romano Platus, e faz parte de uma das suas peças.

${ }^{10}$ A política da psicanálise consiste na sua orientação sobre sua estratégia clínica na direção do tratamento.
} 
Freud, em seu texto intitulado "Novas conferências introdutórias à psicanálise", de 1933, chama a atenção, no capítulo 35 , sobre o fato de que a psicanálise seria inadequada para fornecer uma "visão de mundo", weltanschauung $^{11}$. (FREUD, 1933p. 322).

Isso, de antemão, justificaria a escolha de nosso caminho teórico, pois a psicanálise, enquanto experiência, não daria conta, (e nem seria essa sua proposta), de fornecer ela mesma um direcionamento político específico.

Porém, na medida em que a psicanálise, por si só, não propõe esse tipo de direcionamento, podemos inferir que sua teoria, enquanto "neutra" com relação aos aspectos políticos, poderia tão somente atuar como mantenedora do status quo, na medida em que, não se posicionar e ficar "em cima do muro" contribuiria para que a atuação das classes dominantes agisse livremente, por vezes segregando, excluindo e explorando outras classes e frações de classe. Sabemos que essa afirmação é polemica e suscitadora de outras questões, e é exatamente isto que nos dá a medida do nosso desafio e estimula o debate.

É imperativo admitir que temos hoje grandes novidades por conta das mudanças no cenário da política representativa em toda a parte Ocidental do globo. A mobilização facilitada pela internet é exemplo disso (podemos citar a Primavera Árabe e as eleições que elegeram o presidente norte-americano Donald Trump).

Desde a revolução norte-americana ${ }^{12}$ e do advento da democracia moderna uma nova maneira de fazer política se popularizou, expandiu sua abrangência e capilaridade nas relações sociais.

Hoje ela apresenta novas facetas. A regulamentação do uso da internet e de redes sociais para divulgação de material de cunho político são demandas surgidas nos últimos 20 anos, representando novos desafios para os legisladores, e para o publico consumidor da rede.

Tendo isto em vista, o problema do presente trabalho é: segundo estas novas configurações, como seria a atuação desejada para os novos analistas? Até que ponto se posicionar publicamente com relação à política

\footnotetext{
${ }^{11}$ Esta palavra, por si só, é de difícil tradução, mas acolheremos a tradução fornecida pela editora Companhia das Letras.

${ }^{12}$ Lembrando que a revolução americana é anterior à revolução francesa.
} 
desconfiguraria a proposta psicanalítica de não fornecer uma "visão de mundo"? Tema importante, contemporâneo e, acreditamos, urgente.

\subsection{Discussão}

Historicamente, podemos observar Freud inaugurando uma nova perspectiva de análise sistemática dos processos inconscientes no final do século XIX. Tal sistematização contida em sua proposta de "etiologia sexual das neuroses" ${ }^{13}$ causava certa polêmica por conta, inclusive junto ao círculo científico da época.

Em 1905, ao apresentar os "Três ensaios sobre a teoria da sexualidade" ${ }^{14}$, boa parte da comunidade médica discordou dos argumentos freudianos, o que "forçou" Freud a tratar sua descoberta com rigor científico cada vez mais apurado.

Percebe-se aí uma preocupação freudiana com relação à legitimidade do método e da pesquisa científica com intuito de estender a prática psicanalítica para além do círculo judaico do qual Freud fazia parte, recebendo reconhecimento e boa recepção de sua obra em círculos maiores. A partir deste panorama, começamos a vislumbrar algumas possibilidades de entender movimentos do psicanalista com uma preocupação política.

Dois movimentos distintos, então, se apresentam: o primeiro trata do posicionamento pessoal de Freud frente às questões sensíveis de seu tempo como o crescimento do nazismo e o advento das grandes guerras; e o segundo seria relacionado à expansão e divulgação da psicanálise, bem como suas implicações ${ }^{15}$.

\footnotetext{
${ }^{13}$ FREUD, S. A hereditariedade e a etiologia das neuroses e A sexualidade na etiologia das neuroses. In: Edição Standard Brasileira das Obras Completas de Sigmund Freud. Volume III. 3a ed., Rio de Janeiro: Imago, 1994.

${ }^{14}$ FREUD, S. Três ensaios sobre a Teoria da Sexualidade. Edição Standard Brasileira das Obras Completas de Sigmund Freud. vol. VII. Rio de Janeiro: Imago, 1996.

${ }^{15}$ Deste movimento, cabe mencionar a participação do psicanalista Otto Gross e seu "esquecimento" das atas do movimento psicanalítico, fato por si só polêmico e cheio de conjecturas, que merece um espaço de discussão em outra oportunidade.
} 
Traremos deste fato considerando-o como parte de uma tática ou estratégia política cujo objetivo seria a preservação da imagem pública da psicanálise. Trataremos adiante deste ponto.

Freud não se posicionou sobre questões políticas de maneira clara e assertiva tal como Lacan. Ao que indicam os relatos históricos, parecia um tanto quanto escorregadio em diversos episódios, todavia, quando o nazismo bateu em sua porta, se viu forçado a se posicionar politicamente.

Observamos que, apesar de Freud ter se dedicado à sua obra como um homem da ciência, (no sentido de estar mais ocupado em mostrar ao mundo a estruturação de suas propostas do que interagir socialmente) quando sentiu que seria preciso se implicar politicamente, (seja por conta das guerras ou no período da Anschluss ${ }^{16}$ ), assim o fez, atuando como sujeito político nas questões sobre judeidade e sobre os rumos da civilização.

Temos um movimento similar em Lacan, pois, no período conhecido como Maio de 68, o analista se viu impelido a elaborar sua "teoria dos quatros discursos" ${ }^{\prime 17}$, examinando mais detalhadamente o cenário político e econômico da França, dentre outras observações.

Segundo Pellion (2016: 81), acerca da Teoria dos Quatro Discursos de Lacan e o Maio de 68, cumpre relembrar que

\begin{abstract}
Os acontecimentos de maio de 1968 - manifestações estudantis e operárias, greve geral, eleições antecipadas e em seguida, depois de alguns meses, alertas econômicos em série - vieram interromper o curso previsto do seminário precedente, sobre $O$ ato [psic]analítico. Nesse seminário, Lacan se propunha a desenvolver as razões de sua "Proposição de 9 de outubro de 1967 sobre o psicanalista da Escola" (LACAN, 1967/2003), na qual ele propõe à sua Escola o dispositivo do passe.

[...] penso ser útil lembrar que a "Proposição..." de Lacan ficou muito longe de ser aceita unanimemente, inclusive dentro da Escola que ele havia fundado, com alguns outros, (apenas) três anos antes. Pois quando Lacan falaria da greve (LACAN, 1968-69/2008, pp. 11-25), por exemplo, aquilo que ele diz é também a interpretação da oposição de um bom número de analistas da sua EFP, como uma greve contra a efetivação de seu dispositivo.
\end{abstract}

\footnotetext{
${ }^{16}$ Ancschluss significa anexação. Foi o processo histórico que culminou no episódio histórico ocorrido em 13 de março de 1938, quando a Áustria foi anexada à Alemanha nazista e que teve como consequência a diáspora judaica alemã. Nesta momento, Freud e sua família se mudam às pressas para a Inglaterra, com a ajuda de Ernest Jones. Ver: https://www.freudmuseum.at/online/freud/themen/emigr-e.htm .
}

${ }^{17}$ Cf. LACAN, Jacques. O Seminário: Livro 17. O Avesso da Psicanálise. Rio de Janeiro: Jorge Zahar, 1992. 
Enfim, nesse capítulo do contexto, preciso também mencionar a École Normale Supérieure, que, a partir de 1964, acolhe o seminário. Na época, ela era dirigida por Louis Althusser, eminente comentador de Karl Marx e ele próprio autor de uma teoria dos discursos. Os estudantes que assistem ao seminário são para alguns, inicialmente, para muitos, depois, jovens filósofos engajados, evidentemente sem nenhuma prática clínica, e para os quais o discurso de Lacan vai ter efeito, intencional ou não, de reorientar o desejo de ação da política - o que, em outros países da Europa, levou alguns desses mesmos estudantes a formas variadas de violência - com relação à psicanálise.

É, pois, bem possível que a dita "teoria dos quatro discursos" tenha, de início, visado assegurar a singularidade do discurso analítico. Isto a fim de deslocar sua função tradicional quanto à formação dos analistas em duas direções: 1. a mudança da discursividade misturada, e por vezes confusa, de maio, e, 2. a conformação das aspirações ao engajamento concreto de uma certa classe intelectual.

Para a analista brasileira Miriam Debieux Rosa (2004), a saída da psicanálise de dentro dos consultórios para colaborar para uma visada da cultura se justifica na medida em que:

O inconsciente freudiano é incompatível com a ilusão do individual, da autonomia e da independência no homem, uma vez que afirma a dependência simbólica do desejo do Outro, explicitada na forma como teoriza a constituição do sujeito através do processo edípico. Desta forma, constata-se que, se na análise do sintoma deve-se escutar o não-dito do discurso dos(?) sujeitos, cabe acrescentar a força de determinação dos não-ditos dos enunciados sociais.

Nota-se que a crítica de que a Psicanálise está indo além de seu campo de origem refere-se muito mais a uma direção tomada pelo movimento psicanalítico do que a uma proposta imprópria ou externa a esse campo. Inúmeros são os modos como se pode desenvolver, dentro dos fundamentos éticos e teóricos da psicanálise, uma investigação dos fenômenos sociais, contribuindo para a elucidação de sua eficácia no processo de alienação do sujeito e apontando os laços que possibilitem a sua inclusão como sujeitos do desejo. (ROSA, 2004, p. 340).

Neste ir e vir histórico, nesta observação do passado político quando da época do surgimento da psicanálise, cabe perguntar: quais seriam os pontos de convergência e dissidência dos analistas enquanto sujeitos políticos?

Segundo Almeida (2010: 890),

Em seu texto clássico - O mal-estar na civilização (1980a /1929) - Freud vai destacar que a fonte de sofrimento mais penosa para nós é resultante de nossas relações com os outros. Mal-estar que sempre ronda toda a forma de laço e que é o preço que pagamos pela "perda do paraíso", pelo ingresso no universo simbólico da linguagem. Ao optar pela linguagem o ser humano 
renunciou à possibilidade de acesso ao real, que se tornou para nós algo de impossível significação por meio da linguagem. O mal-estar dos laços é, portanto, o mal-estar da linguagem, que não é capaz de dar conta de todo o real que se apresenta, pois, haverá sempre um impossível de representar. Freud, em Prefácio à juventude desorientada de Aichhorn (1980b/1925), se refere a três profissões consideradas para ele como impossíveis: governar, educar e curar. Mais tarde, em Analise terminável e interminável (1980c /1937) curar é substituído por analisar. Essas profissões representam na teoria freudiana, diferentes maneiras de fazer laço.

Portanto, tais profissões dão a medida do desafio que é governar, da impossibilidade governar, da complexidade de falar de política na psicanálise.

A palavra- fundamental tanto na prática política quanto na experiência analítica - pode ser vista como instrumento em comum para estas duas formas de atuação social: ambas propiciam o surgimento de algo do singular do sujeito que pode servir tanto para mediar conflitos externos quanto para tratá-los em sua face íntima.

Hanna Arendt, em sua obra intitulada A condição humana (2007: 86), explica que "o ser político, o viver numa polis, significava que tudo era dividido mediante palavras e persuasão, e não através de força ou violência". Fazer política, segundo esta autora, seria o desafio de "encontrar as palavras adequadas no momento certo".

Seguindo esta mesma senda, a filósofa brasileira Marilena Chauí (2002), escreve ainda que:

Antes do combate, os guerreiros se reúnem num círculo, formam uma assembleia e cada um, indo ao centro, tem o direito de falar e de ser ouvido, propondo táticas e estratégias para o combate. Após a batalha, novamente os guerreiros se reúnem em círculo, formam uma assembleia e discutem a repartição dos espólios cada qual indo ao centro para exercer seu direito de falar e de escolher sua parte. Perante a assembleia, todo guerreiro pratica dois direitos: o da isegoria (o direito de falar e emitir opinião) e o da isonomia (todos os guerreiros são iguais perante a lei de seu grupo, lei feita pelo próprio grupo). Da assembleia dos guerreiros e da palavra-diálogo, pública e igualitária nasce a polis e é inventada a política. (p. 41-42)

Da origem grega aos consultórios brasileiros, a "palavra-diálogo" seguiu por caminhos e finalidades distintas, porém é interessante observar que, no que tange à tentativa de resolução de conflitos, tal distância pode se estreitar. 
No início do século XIX, Carl von Clausewitz (1996) afirmou que "a guerra não era mais do que a continuação da política". Mais tarde, Michel Foucault (2002) repropôs esse aforismo dizendo que "a política é a guerra continuada por outros meios".

Nesse aspecto, podemos ver a estratégia da política substituindo o embate físico pela "palavra-diálogo", numa certa semelhança à função do analista, que intervém com sua prática no conflito entre as instâncias psíquicas do sujeito, e modificando a relação do sujeito com seus significantes-mestres.

Para além de sua criação e aplicação no setting analítico, podemos prolongar a atuação da psicanálise como chave de interpretação de fenômenos outros, tal como traz Renato Mezan em Freud, pensador da cultura (1985), quando afirma que "desvendando os processos conscientes, (a psicanálise) não teria porque se privar de demonstrar o funcionamento de tais processos em outros domínios da atividade humana" (p. 136).

Ainda que sua vasta produção teórica advenha da experiência clínica, "a psicanálise é uma ciência como outras, um corpo de conhecimento coerente e subsistente por si mesmo, passível de 'aplicação' em territórios estranhos àqueles em que se formaram seus conceitos" (idem, Ibidem, p. 127).

Para Rosa, a psicanálise em extensão - ou extramuros:

diz respeito a uma abordagem - por via da ética e das concepções da psicanálise - de problemáticas que envolvem uma prática psicanalítica que aborda o sujeito enredado nos fenômenos sociais e políticos, e não estritamente ligado à situação do tratamento psicanalítico. Consideramos que esse tipo de pesquisa da Psicanálise - iniciado por Freud e por ele nomeado psicanálise aplicada ${ }^{18}$ - projeta um campo que vem se tornando palco de várias discussões e impasses.

(ROSA, 2004, p.331)

Todavia, sabendo dos impasses e desafios desta proposta, é interessante atentar para a especificidade da psicanálise, que pode colaborar para uma outra perspectiva, sem apagar a importância das especificidades de outros campos do saber.

\footnotetext{
${ }^{18}$ Itálico da autora.
} 
Ainda em Rosa (2010) temos, então, que:

No caso da contribuição da psicanálise ao estudo do campo social e político, não lhe cabe a pretensão de esgotar, por si só, o fenômeno: cabe-lhe esclarecer uma parcela dos seus aspectos, ainda que uma parcela fundamental. Sem pretensão de substituir a análise sociológica, cabe à psicanálise incidir sobre o que escapa a essa análise, isto é, sobre a dimensão inconsciente presente nas práticas sociais. (p. 187)

Na próxima seção exporemos a situação política vivida por Freud e sua elaboração a respeito. A proposta é percorrer brevemente o cenário político da Áustria atentando para outras regiões que the são importantes, bem como fazendo uma observação o mais rica possível de seu contexto sócio-cultural.

\section{2. Áustria: Estado-museu}

O surgimento da psicanálise tem um vínculo inegável com a pessoa de seu fundador, Sigmund Freud, cuja obra se baseia fundamentalmente no manejo do inconsciente, no âmbito da subjetividade. Obviamente a própria psicanálise nos ensina o valor da subjetividade de cada sujeito e de como se faz essa leitura do cenário e dos Outros que Ihe cercam (falaremos disso mais adiante), todavia, percorremos aqui o contexto de surgimento da psicanálise no intuito de buscar informações políticas relevantes de seu tempo.

Freud nasceu em Viena em 06 de maio de 1856, oriundo de uma família judia, filho mais velho de oito irmãos, tendo como pais Jacob Freud e Amália Nathansohn. Viveu em um período de intensas transformações políticas em sua região, que culminaram na instituição do Império Austro-Húngaro, poucos anos depois de seu nascimento, em 1867.

Viena se mostrara uma cidade afeita às artes, ao teatro, uma cidade onde o lazer parecia imperar, como nos comenta Mezan (1985): "o lazer parece flutuar na atmosfera, sem que se perceba como ele se articula com o mundo cotidiano, com o mundo do trabalho".

Stefan Zweig (1977 apud MEZAN, 1985: 15) em sua autobiografia (Die WeltvonGestern), descreve a Viena de sua memória, sobre o que Mezan 
pontua: "Tocar música, dançar, ir ao teatro, conduzir-se com bom gosto e propriedade, eram em Viena coisas consideradas como arte especial". E ainda acrescenta que as prioridades se configuravam, então, da seguinte forma:

O mais importante tanto na vida dos indivíduos quanto na da comunidade, não eram as questões militares, políticas ou comerciais; a primeira página do jornal a ser lida por um cidadão comum não era a das discussões no Parlamento ou a dos acontecimentos internacionais, mas as do programa de teatro. (ZWEIG,1977, apud MEZAN, 1985:. 23)

Neste clima cultural e, de certa forma, alheio às questões políticas, a Áustria vivia seu período de revolução industrial. Sob o governo de Metternich (que durou de 1815-1848), que se preocupava em espantar os fantasmas das ideias liberais da Revolução Francesa com censura e polícia, a movimentação cultural focava na "afirmação da legitimidade da dinastia" e em atividades não comprometedoras, como um contato mais íntimo de rodas de conversa e de dança.

Neste período, a valsa de Strauss pai começa a se popularizar, tendo então, um efeito interessante:

Refúgio do particular, evocando o amor e a interioridade burguesa, a valsa ao mesmo tempo limita esta interioridade à sua camada mais superficial, a da pura afirmação de si na habilidade dos passos ritmados, e restringe o campo da intersubjetividade ao enlace levemente erótico dos pares abraçados. Eis porque a paixão de Viena pela nova dança se coaduna perfeitamente com 0 esforço de despolitização, isto é, com a redução de todos à esfera de meros particulares, sem voz na condução dos assuntos públicos: o fechamento do ambiente político por meio da censura e do arbítrio deixa, como único território livre para a expressão, a dimensão do particular, e a locução "bailes públicos" exprime bem a degradação da esfera do "público" à pura condição de espaço do divertimento sem consequências. (MEZAN, 1985: 26).

Assim, Viena permaneceu sem essa abertura essencial para as novidades, em contraponto ao que ocorria em Paris no mesmo período, por exemplo. "Viena se acomodava em seu provincianismo, renunciando à função de metrópole europeia que fora a sua no século barroco". (MEZAN, 1985: 27).

Essa apatia política e cultural fez com que Viena habitasse essa áurea de "Estado-museu", termo cunhado por Hermann Broch (apud MEZAN, 1985: 
45) que, em seu livro Hofmannsthaletson Temps (1966), se debruça sobre as questões artísticas dessa região no período acima referido.

Esta obra também é utilizada largamente por Mezan para abordar as questões artísticas da Áustria no século XIX, mas sua interpretação serve ainda para uma compor uma visão mais alargada do momento, sobretudo em Viena.

Neste momento, a economia austríaca baseava-se basicamente na exploração do ferro e a fiação dos tecidos leves, (BROCH, p.42 apud MEZAN,1985: 50). Todavia, o ano de 1948 trouxe um movimento liberalista diferente para os austríacos. Mezan, então, discorre:

De forma geral, a reação dos acontecimentos de 1948 pode ser caracterizada como uma abertura econômica ao capitalismo, vinculada a uma recusa dos princípios políticos do liberalismo; estranha conjunção, favorecida no entanto pelo peso extremamente grande da aristocracia na estrutura social do Império. Esta aristocracia, se por um lado não hesita em investir seu capital na indústria e nos bancos, por outro conserva o predomínio inconteste no setor político, aureolada por seu prestígio social. É certo que o centralismo coloca nas mãos do Imperador um considerável poder de decisão, e que a eficácia da burocracia retira pouco a pouco da nobreza suas funções administrativas; mas como classe, ela é ainda a detentora da hegemonia, apoiada na propriedade fundiária, na nomeação de seus membros para os postos de confiança do governo, e do exército e na trama de interesses recíprocos que a une à Coroa.E então, em 1867 o Imperador Francisco José é coroado em Budapeste e dá nascimento ao Império Austro-Húngaro (que perdurará até 1918). Porém, a parte austríaca do Império sofre com a crise de 1873, cenário onde milhares de pequenos investidores, falências em série de instituições financeiras geraram uma crise econômica substancial. Porém, mesmo com a retomada econômica pouco tempo depois, não foi suficiente para a pequena burguesia e para a classe operária "confiarem nas virtudes do liberalismo, desconfiança que se expressará no surgimento de partidos políticos de orientação antiliberal a partir da década de 1880". (MEZAN, 1985, p. 46)

Depois desses adventos, o cenário político na Áustria começa a mudar de forma visível: o Império Austro-Húngaro era composto de uma variabilidade étnica, linguística e cultural difíceis de conciliar, gerando numa disputa acirrada entre as nacionalidades.

Aí, então, a luta política começa seu protagonismo graças ao surgimento da classe operária: "as manifestações operárias começam a se tornar frequentes a partir da legalização dos sindicatos em 1870; a instauração de uma moderada legislação social na década de 1880". (MEZAN, 1985: 49). 
Ainda citando o autor brasileiro:

Viena é assim o palco destas lutas, no âmbito das nacionalidades e no da luta de classes imbricada com a questão nacional; mas, se no parlamento sediado na Ringstrasse vêm se esses múltiplos antagonismos, a indiferença dos vienenses quanto a eles é quase completa. (Idem, Ibidem, p. 50).

Essa apatia política instaurada em Viena durante a juventude de Freud poderia se desdobrar em um trabalho mais alheio a estes temas na obra do psicanalista. Todavia, para além deste enfoque diretamente político, Freud vislumbrava um potencial de criação teórica e um reconhecimento por parte da comunidade científica que podemos observar como sendo uma faceta estimulada no círculo vienense, como lemos adiante:

Lugar formal de um combate cujas bases reais the são totalmente estranhas, Viena mostra antes o aspecto de uma harmonia étnica. $O$ brilho da capital faz com que a ela os melhores elementos de várias etnias, desejosos de fazer carreira, de entrar na Universidade, de atingirem a fama nos diferentes domínios da arte e das ciências. Esta função aglutinadora, Viena aceita-a e a preenche da melhor forma possível. É através dela que se dá a convivência dos diferentes grupos, que não exclui as barreiras de classe, mas as reabsorve na atmosfera polida e jovial que [já] evocamos. (Ibidem, p. 52) 


\section{Cenário contemporâneo}

Nesta seção, iremos analisar as causas e conseqüências de dois fatos históricos contemporâneos que tocam diretamente o campo da psicanálise a partir de um paradigma teórico de orientação.

Os fatos são, objetivamente, a criação da ZADIG na França, e a última proposta de regulamentação da psicanálise no Brasil, tendo a união das escolas e institutos de psicanálise como desdobramento deste último acontecimento. O paradigma teórico de orientação a que nos referimos é a Proposição de nove de outubro de 1967 de Lacan.

\subsection{Tentativa de regulamentação}

A regulamentação da psicanálise no mundo ocidental já seria, por si, tema abrangente e prenhe de questões. Freud, Lacan, Jung, entre outros psicanalistas, eram médicos de formação, porém, Freud ressaltou no texto "A questão da análise leiga", de 1926, a importância de colocar a psicanálise em um lugar distinto da prática da medicina. Ele escreve que "a análise é leiga: é uma experiência subjetiva, singular, que implica uma ética peculiar". (FREUD, 1996).

Neste sentido, ele se determina a uma disputa do campo da Psicanálise, defendendo a posição de que a sua profissionalização feriria os fundamentos da formação do analista. Mais tarde, na mesma direção, Lacan (1998) assegura firme: "para aquele que deseja autorizar-se, autorizar-se analista, é necessário a ousadia de começar por sua própria análise. O analista é conseqüência do ato analítico, e a Psicanálise não se transmite como qualquer outro saber.".

Da mesma forma, Santanna (2014) afirma que

A experiência analítica não pode ser regulamentada, pois ela é uma experiência subjetiva que leva a uma transformação do sujeito e não a um acúmulo de saber técnico e nem a um reforço na crença do Outro que sabe.Como se pode constatar tomando apenas alguns fatos da história do movimento psicanalítico, esta é uma questão de cunho eminentemente político 
que, nos dias mais recentes, reaparece ameaçando a Psicanálise "com o avanço disciplinar no campo do mal viver" a partir de uma nova ofensiva regulamentadora, como assinala Laurent, citando Milner no seu discurso de posse.Responder a esta questão significa a necessidade de prosseguir com um debate que se inaugura com Freud e hoje envolve pensadores destacados da intelectualidade francesa, principalmente aqueles dos grupos ligados à área psíquica, destacando-se, dentre esses, psicanalistas liderados por Jacques Alain Miller, os quais buscam assegurar uma posição ética que impeça as tentativas de cercear o exercício da psicanálise e lhe garanta os fundamentos.

Hoje, essa distância entre a psicanálise e a medicina é discutida, inclusive, no âmbito das psicologias, posto que estas, em sua maioria, levam em conta as questões conscientes como pressuposto fundamental da direção de seus tratamentos, divergindo da proposta freudiana.

Todavia, faremos a escolha por um recorte que visa somente abordar o enlace de movimentações políticas incidindo diretamente na práxis psicanalítica e da atuação dos analistas como resposta a estas políticas.

Abordaremos para isso duas situações distintas que exemplificam este cenário. A primeira, o exemplo suscitado pela aprovação na assembleia francesa da Emenda Accoyer em 2003, que visava regulamentar a atuação de psicoterapeutas no país. Traremos, ainda, a proposta que visa regulamentar a psicanálise enquanto profissão no Brasil, tramitando no poder legislativo nacional.

\subsubsection{Emenda Accoyer}

Em outubro de 2003, a Assembleia francesa aprovou (sem debates) uma regulamentação da prática psicoterapêutica. A emenda, apelidada de Emenda Accoyer (sobrenome do deputado que a propôs), restringia a prática psicoterapêutica a médicos, psiquiatras e psicólogos com especificações elencadas no decreto. Os profissionais que não possuíssem estas qualificações, mas que já estivessem atuando há mais de cinco anos nestas práticas, seriam avaliados por um júri organizado por indicação de ministros e de profissionais do ensino superior. 
A psicanálise não foi mencionada diretamente no texto do decreto, mas a práxis analítica seria afetada de maneira objetiva. Dada a variabilidade na formação analítica em solo francês, a reação das escolas psicanalíticas foi diversa. Tal emenda iria contra pressupostos freudianos básicos no que tange à Análise Leiga, conforme já mencionado, e a regulamentação de sua prática por parte do Estado. De maneira geral, as Escolas de formação em psicanálise regulam, elas mesmas, sua atuação, e este decreto poriam fim a esta metodologia e autonomia.

Segundo Santanna (2014), esta tentativa de regulamentação, para além da França, causou certo ruído uma vez que implicava em uma série de recomendações e consequências que a distanciavam cada vez mais das concepções de análise leiga tanto de Freud quanto de Lacan.

Segundo ela,

Saindo da França, as posições da Alemanha e da Itália foram relativamente distintas entre si quanto à regulamentação da profissão de psicoterapeuta, mas em ambos os países as conseqüências foram danosas para os analistas leigos já que estes ficaram excluídos do acesso à formação e ao título. No caso da Alemanha, a Psicanálise está explicitamente integrada às psicoterapias relacionais, o que a coloca em uma situação muito crítica: o analista é obrigado a elaborar um relatório diagnóstico e prognóstico sobre a duração do tratamento. Como efeito dessas mudanças, o acento na Avaliação é a palavra de ordem da nova Política de Saúde. Ela incide "sobre o tratamento, as estratégias preventivas, diagnósticas e terapêuticas, fazendo com que na industrialização da medicina moderna, a medicina fundamentada na experiência ceda lugar à medicina fundamentada na prova, ou seja, a cultura estatística vença a cultura do caso."

O psicanalista Fernando Aguiar, professor de psicologia da UFSC expõe:

Nos meios de comunicação, em particular na mídia eletrônica, o acontecimento propiciou entre as partes direta ou indiretamente implicadas uma discussão de grandes proporções, não fosse esta uma característica nacional. Contudo, para além das fronteiras francesas, mesmo européias, resta o óbvio interesse de acompanhar com atenção seus desdobramentos, resgatar sua história, que remonta a pelo menos duas décadas, e dela retirar subsídios que, guardadas as especificidades de cada país, possam ser úteis às nossas próprias e hodiernas discussões. (Como se sabe, no Congresso brasileiro, há um projeto 
de lei de regulamentação da profissão de psicanalista, proposto pelo deputado Éber Silva.) ${ }^{19}$

O mesmo autor expõe ainda outras considerações importantes ${ }^{20}$, como as que seguem abaixo:

Agora, ante um inimigo externo comum, abriu-se a possibilidade de que a discussão de questões ligadas à transmissão, à formação, à "análise leiga" e à própria condução da análise - de fato na origem de todas as rupturas, remotas ou recentes, e do grande número de associações e de instituições existentes hoje em dia - resultasse na reafirmação de princípios comuns, mesmo levando em conta afinidades particulares e divergências teóricas pontuais. Dito de outra maneira, tornou-se crucial a necessidade de explicitar sem ambigüidade para 0 público leigo o que diferencia a psicanálise do vasto domínio das psicoterapias, ao mesmo tempo que sustentando o corpo doutrinário que lhe permanece fundador, bem como a fecundidade do método freudiano.

Se, por um lado, uma parte considerável do campo da psicanálise asseverava que precisava constituir em torno de si uma barreira de proteção que a distinguisse consistentemente das iniciativas consideradas "pouco criteriosas" ou pouco profissionais e que atendiam sob a alcunha de "psicoterapia"; por outro lado, parte do campo psicanalítico se recusava a se submeter a regras criadas fora do próprio campo ou ser regulamentada pelo Estado.

\subsection{O exemplo de Massimo Recalcati}

No sentido de alimentar o debate, seguimos com a apresentação do exemplo de Massimo Recalcati, que, gozando da relativa autonomia construída no campo psicanalítico, considerou a possibilidade de firmar posicionamento político pouco ortodoxo do ponto de vista da ética psicanalítica construída coletivamente.

\footnotetext{
${ }^{19}$ Disponível em: http://www2.uol.com.br/percurso/main/pcs34/34Aguiar.htm . Acesso em 14 de maio de 2018.

${ }^{20}$ Disponível em: https://sobrevolandolacanquotidien.blogspot.com/2017/09/controversias-portemas.html. Acesso em 20 de fevereiro de 2018.
} 
O psicanalista italiano Massimo Recalcati causou furor na cena psicanalítica europeia ao se ligar politicamente ao ex-primeiro ministro italiano Matteo Renzi.

À época, Renzi, do partido democrata, era tido como um conservador e recebia muitas críticas por parte da esquerda italiana. Recalcati serviu a Renzi como uma espécie de tutor, de conselheiro, e teria fundado a escola partidária do partido democrata, batizando-a de Paolo Passolini.

Nas palavras de, Recalcati ${ }^{21}$ :

A idéia surgiu na minha cabeça graças a dois tropeços. O primeiro contingente: o da derrota no referendo. O segundo é mais estrutural: a dificuldade do partido para falar às novas gerações. São dois tropeços ligados, na realidade, um ao outro porque grande parte da derrota no referendo foi causada precisamente pela dificuldade de convencer o mundo dos jovens sobre a bondade dessa reforma.

Jacques Alain-Miller ${ }^{22}$, considerando a polêmica criada em torno não do nome de Lacan e nem objetivamente do uso da psicanálise por um membro muito conhecido e popular do Campo Lacaniano na Itália, mas por conta de a escola que ajuda a fundar homenagear o poeta que fora expulso do $\mathrm{PCl}$ (Partido Comunista Italiano) em 26 de outubro de 1949, e enquanto administrador do patrimônio intelectual de Lacan, concedeu uma entrevista para o tablóide italiano II Fatto Quotidiano ${ }^{23}$, criticando duramente a postura de Recalcati, como veremos em trechos a seguir.

Assegura Afirma Miller que:

\footnotetext{
${ }^{21}$ Disponível em: http://www.vita.it/it/article/2017/06/06/che-ci-azzecca-pier-paolo-pasolini-conil-pd-e-polemica-tra-i-lacanian/143636/. Acesso em 03 de abril de 2018.

22 Jacques-Alain Miller, um dos psicanalistas vivos mais conhecidos, fala. Estudante e examinador do mestre Jacques Lacan. Miller chegou a Turim para participar da conferência nacional da escola lacaniana. Mas nos corredores da universidade, assim como na psicanálise, falamos sobre política local. Surgiu o caso de Recalcati: um acadêmico italiano de Lacan chamado por MatteoRenzi para lançar a escola partidária do Partido Democrata. A polêmica aparentemente toda italiana chegou ao exterior, começando por Paris.

${ }^{23}$ Entrevista de Jacques Alain-Miller para o jornal italiano II Fatto Quotidiano no dia 27 de maio de 2017 por FerruccioSansa. Disponível em: http://www.inchiestaonline.it/politica/perche-lopsicoanalista-lacaniano-massimo-recalcati-si-e-innamorato-di-renzi/ . Acesso em 10 de janeiro de 2018.
} 
Um psicanalista como Massimo Recalcati não pode colocar seu conhecimento a serviço de um partido político. Ele não pode usar as técnicas de sua ciência para atrair jovens. E então em uma escola com o nome de Pier Paolo Pasolini, é demais! (...) Aqueles que fazem o nosso trabalho não devem ter rótulos políticos sobre eles.

Para justificar o motivo pelo qual se escolheu o nome de Pasolini para ser homenageado na escola, Recalcati explicou:

Pasolini foi um dos intelectuais mais generosos e anti-conformistas em nosso país. Sua força não excluía a contradição: ele era marxista, mas profundamente atraído pela cultura cristã; crítico do aparato de $\mathrm{PCl}$, mas capaz de reconhecer o lugar de resistência cultural e antropológica do $\mathrm{PCl}$ aos mitos do consumismo; foi para o protesto contra o sistema, mas em 1968 ficou do lado dos servidores do estado contra o movimento estudantil; ele era um leigo, defensor da causa homossexual, mas um opositor decisivo do aborto; generoso até o sacrifício de si mesmo, mas também uma estrela que não desdenhou seu papel midiático; ele era um nostálgico da tradição e cultura camponesas, mas também um extraordinário experimentador de novas linguagens artísticas. Eu acho que os grandes mestres são acima de tudo um estilo. E Pasolini incorporou o estilo de um intelectual comprometido, envolvido na vida da comunidade, livre do peso da ideologia, com o coração à esquerda, uma crítica irredutível dos falsos mitos do desenvolvimento sem progresso. Em Pasolini convergem também as múltiplas almas do Pd: a alma da derivação socialista e comunista, a do cristianismo e do catolicismo social e a ecológica.

\subsection{Criação da ZADIG}

No início do ano de 2017 a França se via às voltas com suas eleições presidenciais. A candidata de extrema-direita Marine Le Pen, do partido Frente Nacional, apontava nas pesquisas eleitorais como possível vencedora das eleições.

Entre as pautas defendidas em seu plano de governo estavam medidas protetoras radicais para coibir a migração de população estrangeira sem autorização para o solo francês e negar acesso destes aos serviços de saúde e de educação gratuitos no país. 
Propunha, também, a saída de alguns tratados comerciais internacionais de forma a proteger a economia francesa e investir no aumento de gastos com a defesa criando ainda 40 mil vagas nos presídios do pais ${ }^{24}$.

Com a iminência de um governo austero e que propunha de certa forma sufocar diferenças entre os sujeitos, a Escola da Causa Freudiana em Paris instituição de transmissão de psicanálise influente no mundo inteiro, e uma das herdeiras do legado de Jacques Lacan - resolveu se posicionar.

$\mathrm{Na}$ figura de seu maior expoente, o psicanalista francês Jacques AlainMiller propôs uma atuação desejável para os psicanalistas membros da Escola frente a estas propostas da extrema-direita.

Para isso, Miller formula a criação da ZADIG (Zero Abjection Democratic International Group) que visa assinalar "a diferença entre a posição do analista que se engaja a título pessoal, como cidadão, em um partido político de sua escolha, e a política da psicanálise que se move através de seu coletivo" (ANGELA HARARI, 2017) ${ }^{25}$

A importância de se pensar a ZADIG neste trabalho vai de encontro a proposta de um posicionamento claro de psicanalistas frente às questões políticas de seu tempo.

Teria Miller agido de forma coerente ao exortar seus colegas membros a ir contra Le Pen? Sabendo que o candidato Melanchon (de corrente política oposta a de Le Pen) não teria chances já que estava mal cotado nas pesquisas, apoiar Manuel Macron teria sido um posicionamento correto?

\subsection{Proposição de nove de outubro de 1967}

A Proposição de nove de outubro de 1967 é um texto escrito por Lacan que fornece as bases para atuação da Escola enquanto lugar de legitimidade de transmissão em psicanálise e tem um caráter de recomendação. Faz, ainda, ponderações sobre o dispositivo do passe analítico - dispositivo que atesta a

24 Disponível em: https://www.publico.pt/2017/04/24/mundo/noticia/o-que-defende-le-pen1769890. Acesso em 10 de janeiro de 2018.

${ }^{25}$ Disponível em: FONTE https://www.ebp.org.br/correio express/000/texto2.html. Acesso em 16 de maio de 2018. 
passagem do sujeito segundo seu próprio relato do percurso de análise pessoal em sua travessia de analisando a analista.

Essa proposição surge da preocupação de Lacan em estruturar a formação do analista que, em seu processo contínuo de formação, necessitava, dentre outras coisas, de uma espécie de avaliação - através de testemunho - visando conferir os efeitos de sua análise, bem como organizar a atuação da Escola e de seus pares.

A importância desse escrito vai de encontro ao interesse dos analistas no sentido de ser a Escola - e não outro lugar, como a academia ou alguma espécie de curso - que colabora com a formação do analista.

Os efeitos disso são muitos:

1. na medida em que a psicanálise não se propõe a uma regulamentação sob a égide do Estado isso significa que não são outros senão seus próprios pares que podem atestar a eficácia de uma análise e a consequente passagem a analista.

2. Tal documento serve, ainda, como argumento contra a regulamentação pretendida pelo Estado que, vez ou outra, torna a ser tema no legislativo brasileiro, fazendo com que instituições analíticas das mais variadas vertentes se unam contra tal regulamentação.

Se, por um lado, com essa falta de regulamentação, não se forneça parâmetros para deliberar sobre o "título" de psicanalista e que, portanto, implica no fato de nada poder impedir que qualquer pessoa abra um consultório psicanalítico, por outro, a indicação freudiana de que "o analista se forma no divã" se mantém acesa, sem a intervenção do Estado, sendo assim, uma profissão, de certo modo, subversiva, obedecendo tão somente aos registros do inconsciente, do sujeito desejante. 


\section{Considerações Finais}

É importante avaliar o desdobramento destas ações que implicam direta e indiretamente na função dos analistas e na sua relação com sociedade civil, bem como avançar no amadurecimento das ponderações que tratem destes temas, dada a produção relativamente pequena nestes assuntos, se compararmos à produção ligada especificamente à clínica analítica.

$\mathrm{Na}$ primeira parte do trabalho apresentaremos brevemente o contexto sociohistórico da Áustria do final do século XIX, época do nascimento de Freud e, posteriormente, do surgimento da psicanálise enquanto novidade científica. Percorreremos os acontecimentos políticos relativos a esse período e fizemos um inventário do nível dos impactos destes acontecimentos na obra freudiana.

A polaridade política apresentada no cenário das últimas eleições nos Estados Unidos, na França e no Brasil, (só pra citar alguns exemplos de democracia representativa neste lado do hemisfério) geraram e ainda geram muitas questões importantes.

Se por um lado vemos na extrema direita, o flerte com o fascismo, o autoritarismo e a segregação - formas de ferida do ideal civilizatório, por outro lado, vemos a popularização de uma resistência multifacetada no discurso e na práxis feminista, nos movimentos antirracistas, na luta contra a lgbtfobia, e outras tantas formas de se colocar contra essa máquina de moer gente denominada capitalismo.

Intuitivamente, localizaria a popularização desses discursos de resistência no momento de criação das políticas de inclusão da camada mais popular da população (no exemplo brasileiro) na cena acadêmica. Na medida em que índios, negros e pobres tiveram acesso a este lugar, podiam (e podem), reivindicar uma representatividade que antes não era tão reverberada e ocupar lugares nunca antes pensáveis na estrutura social, deslocando os critérios de distinção entre as classes sociais..

O advento da popularização da internet também colabora para a disseminação desse tipo de pauta, (agora posso destacar tanto a popularização da agenda de extrema-direita quanto a disseminação da agenda combativa), criando um cenário novo para os dias atuais. 
Lançadas essas bases, parece irresistível o convite a se posicionar de um lado específico, como se não houvesse possibilidade para além das polarizações tipicamente brasileiras consagradas na última quadra histórica: ser "coxinha" ou "mortadela".

É deste momento que este trabalho pretendeu falar e lançar algumas ponderações não com o intuito de saturar o debate e muito menos de oferecer soluções sobre o impasse lançado, mas apenas oxigenar o debate, lançando elementos teóricos, metodológicos, éticos e políticos que se imbricam na práxis profissional do psicanalista.

De que lado estão os psicanalistas? Existe um lado para os psicanalistas? Devem estes se posicionar publicamente quanto a questões políticas que se constituem como pautas para a sociedade? Quais seriam as implicações para os psicanalistas cujos pacientes, por ventura, se posicionem em uma corrente política contrária? Estaria o psicanalista unido à psicanálise por um laço autoritário como o militarismo ou um sacerdócio, cujos dogmas são inquestionáveis? Em que medida um posicionamento específico de orientação das Escolas também não colabora para o apagamento das diferenças entre os analistas-sujeitos tão privilegiadas no discurso analítico? Não seria ditador impor uma direção única na formação dos nossos pares? Ou seria um convite sensato?

Não creio que sejam simples as respostas para estas questões, nem pretende-se esgotar o assunto nessas paginas ainda rasas. Mas dada a proliferação deste tipo de assunto nos eventos ligados à psicanálise, a produção de discussão sobre tal assunto tem crescido exponencialmente. 


\section{Referências Bibliográficas}

ALMEIDA, Rita de Cássia de Araújo. O discurso do analista e a invenção de uma escola em movimento. In:REVISTA MAL-ESTAR E SUBJETIVIDADE. Fortaleza - Vol. X - № 3, set/2010.

BOURDIEU, Pierre. Os usos sociais da ciência. Por uma sociologia clínica do campo científico. Editora UNESP/INRA, São Paulo, 2004.

BOBBIO, Norberto. A era dos direitos. Nova ed. - Rio de Janeiro: Elsevier, 2004.

CHAUÍ, Marilena. Introdução à história da Filosofia: Dos pré-socráticos a Aristóteles. Vol. 01. 2a ed. rev. e ampl. São Paulo: Companhia das Letras, 2002.

CLAUSEWITZ, Carl von. Da guerra. São Paulo: Martins Fontes, 1996.

FOUCAULT, Michel. Em defesa da sociedade - curso no Collège de France (1975-76). São Paulo: Martins Fontes, 2002.

FREUD, S. Totem e tabu. Rio de Janeiro: Imago, 1996. Imago, 1933.

Novas conferências introdutórias à psicanálise. Rio de Janeiro:

FREUD, S. A hereditariedade e a etiologia das neuroses e A sexualidade na etiologia das neuroses. Edição Standard Brasileira das Obras Completas de Sigmund Freud. Volume III. 3a ed., Rio de Janeiro: Imago, 1994.

Três ensaios sobre a Teoria da Sexualidade. Edição Standard Brasileira das Obras Completas de Sigmund Freud. vol. VII. Rio de Janeiro: Imago, 1996.

FREUD, Sigmund. Pós - escrito: A questão da análise leiga. Tradução Eduardo Vidal. In: A análise é leiga: da formação do psicanalista, Rio de Janeiro, ano 22, n.32, 2003.

A questão da análise leiga - 1926. Edição standard brasileira das obras psicológicas completas de Sigmund Freud, 20. Rio de Janeiro: Imago, 1996.

LACAN, J. O eu e o outro. In: O Seminário - Livro 1: os escritos técnicos de Freud. Rio de Janeiro, Jorge Zahar, 1979a.

LACAN, J. O sujeito e o outro (I): a alienação. In: O Seminário - Livro 11: os quatro conceitos fundamentais da psicanálise. Rio de Janeiro, Jorge Zahar, 1979b..

LACAN, J. Introdução do grande outro. In: O Seminário - Livro 2: o eu na teoria de Freud e na técnica da psicanálise. Rio de Janeiro, Jorge Zahar, 1985. 
LACAN, Jacques. O Seminário: Livro 17. O Avesso da Psicanálise. Rio de Janeiro: Jorge Zahar, 1992.

Função e campo da fala e da linguagem. In: Escritos. Rio de Janeiro: Jorge Zahar, 1998.

Situação da Psicanálise e formação do psicanalista em 1956. In: Escritos. Rio de Janeiro: Zahar, 1998.

Proposição de 9 de outubro de 1967. In: Outros escritos. Rio de Janeiro: Jorge Zahar, 2003.

MARX, Karl. Para a crítica da economia política. Salário, preço e lucro. O rendimento e suas fontes. São Paulo: Abril Cultural, 1982.

MARX, Karl e ENGELS, Frederich. A ideologia alemã. São Paulo: Boitempo, 2007.

MARX, K. O 18 Brumário de Luis Bonaparte. Boitempo, São Paulo, 2011.

MEZAN, R. Freud, pensador da cultura. São Paulo, Editora Brasiliense, 1985.

NETTO, José Paulo. Introdução ao método da teoria social. In: Serviço Social: direitos sociais e competências profissionais. UNB/CFESS/ABEPSS, Brasília, 2009.

PELLION, Frédéric. ENSAIO: A propósito dos discursos. In: STYLUS (Rio J.). Periódicos Eletrônicos em Psicologia. No.33, Rio de Janeiro novembro de $2016 . \quad$ Disponível em: http://pepsic.bvsalud.org/scielo.php?script=sci arttext\&pid=S1676157X2016000200007. Acesso em 15 de janeiro de 2018.

ROSA, Mirian Debieux. A pesquisa psicanalítica dos fenômenos sociais e políticos: metodologia e fundamentação teórica. In: REVISTA MAL-ESTAR E SUBJETIVIDADE. Fortaleza, V. IV,N. 2, setembro, 2004.

SANTANNA, Vera Lúcia. Sobre a análise leiga. EL PSICOANALITICO PUBLICACIÓN DE PSICANÁLISIS, SOCIEDAD, SUBJETIVIDAD, Y ARTE. No. 21, em dezembro de 2014. 